\title{
BLOOD BANK SCENARIO DURING COVID 19 PANDEMIC- EXPERIENCE FROM TERTIARY CARE HOSPITAL
}

\section{Pathology}

Dr Sandhya V Poflee Associate Professor, Department of Pathology, Government Medical College and Hospital, Nagpur.

Dr Archana L Khade*

Dr Sanjay N Parate Dr Dinkar T Kumbhalkar
Assistant Professor, Department of Pathology, Government Medical College and Hospital, Nagpur. *Corresponding Author

Professor and Head of Department of Pathology, superspeciality hospital, Nagpur and Medical director, Model blood bank, Government Medical College and Hospital, Nagpur.

Professor and Head, Department of Pathology, Government Medical College and Hospital, Nagpur.

\section{ABSTRACT}

Background: From initial declaration of outbreak of Severe acute respiratory syndrome corona virus 2 (SARS-CoV-2) infections in December 2019 to declaration of pandemic on 11th March 2020 by World health organization (WHO), vast changes were noticed on healthcare scenario. Irrespective of projection in media, we observed specific changes only in some of the blood banking activities.

Objectives: To evaluate changes in scenario at our blood bank during lockdown (restricted movements) period of COVID 19 pandemic. To get insight into the causation of the changes was the aim of this study.

Material And Methods: Number of blood units collected, blood and blood products issued in parallel months of 2019 and 2020 were compared. Voluntary blood donation (VBD) activities carried out during lockdown period were also scrutinized, during respective months. Blood bank data was analyzed and statistical significance and correlation was evaluated.

Results: Statistically significant increase was observed in utilization blood and blood products and collection from VBD camps in the months of March to May 2020, when compared with the respective months of year 2019.Major blood collection during March to May 2020 was from voluntary blood donation camps organized in rural areas. No significant difference was found in transfusion transmitted disease (TTD) positivity of blood unit collected during parallel months of 2019 and 2020.

Conclusion: Even with COVID 19 pandemic, routine blood bank activities in our blood bank were not adversely affected. This was possible with timely guidelines from the concerned authorities, administrative support and proper mobilization of available resources during this period.

\section{KEYWORDS}

COVID-19 pandemic, lockdown, blood banking activities, voluntary blood donation, voluntary blood donation camps

\section{INTRODUCTION:}

World health organisation (WHO), declared COVID- 19 as a global Pandemic in March 2020. ${ }^{1}$ The unprecedented situation created due to this pandemic exposed lack of preparedness and insufficiency of diagnostic and therapeutic health care facilities at many medical centres in India. Reduced blood stocks and scarcity of testing kits and others consumables due to restrictions on transport during lockdown period were the major difficulties faced by transfusion centres.

This study has tried to evaluate impact of COVID 19 pandemic situation on day to day working of a large blood bank affiliated to a Tertiary Care hospital and Medical Institute of central India.

\section{MATERIALAND METHODS:}

This observational study analysed blood bank records of the largest Government blood bank of Central India. The blood bank is located in the premises of a Tertiary Care Hospital and Teaching Institute and entitled with the status of Model blood bank with yearly collection of more than 10,000 blood units since $27 / 10 / 2009$. The largest blood bank of the region holds a valid license granted by Food and Drug Administration (FDA) for collection and issue of whole blood as well as blood components in the form of packed red cell (PRC), fresh frozen plasma (FFP) and platelets. The blood bank data about collection, utilization and discard of blood units during months of March to May of year 2019 and 2020 was compared. Statistical analysis was carried out based on chi square test and calculation of $p$ value.

\section{Observations:}

This observational study compared the data between month of March to May of year 2019 and 2020. All the blood units were collected from blood donors between age group of 18 to 60 years of age and the donors were fulfilling all the standard donor selection criteria. Maximum number of donors were healthy and middle aged. From the declaration of pandemic on $11^{\text {th }}$ March 2020, travel history of the donors and their contacts was asked in details as per guidelines.

\section{RESULTS:}

As seen from table 1, VBD in blood bank during months of March to May of year 2020 showed statistically significant increase with $p$ value
$<0.05$ when compared with months of March to May of year 2019

Table 1: Showing Comparative Data Of Collection, Utilization And Discards Of Blood Units During March To May 2019 \& 2020

\begin{tabular}{|l|l|l|l|l|l|l|l|}
\hline Sr. no & \multicolumn{1}{l|}{ March } & \multicolumn{2}{l|}{ April } & \multicolumn{2}{l|}{ May } & \\
\cline { 2 - 7 } & 2019 & 2020 & 2019 & 2020 & 2019 & 2020 & $\mathrm{P}$ value \\
\hline $\begin{array}{l}\text { No of voluntary blood } \\
\text { donations in parent } \\
\text { blood bank }\end{array}$ & 615 & $\mathbf{7 5 8}$ & 806 & $\mathbf{8 0 8}$ & $\mathbf{7 4 4}$ & $\mathbf{7 3 5}$ & $\mathrm{P}<0.05$ \\
\hline $\begin{array}{l}\text { No of blood bags } \\
\text { transferred in blood } \\
\text { bank from peripheral } \\
\text { blood bank }\end{array}$ & 312 & $\mathbf{5 9 5}$ & $\mathbf{1 7 8}$ & $\mathbf{3 1 5}$ & 153 & $\mathbf{2 1 0}$ & $\mathrm{P}<0.05$ \\
\hline $\begin{array}{l}\text { No of blood and blood } \\
\text { products utilization }\end{array}$ & 1580 & $\mathbf{1 7 5 1}$ & $\mathbf{1 2 3 6}$ & $\mathbf{1 5 5 3}$ & $\mathbf{1 2 4 6}$ & $\mathbf{1 6 9 8}$ & $\mathrm{P}<0.05$ \\
\hline $\begin{array}{l}\text { No of blood and blood } \\
\text { products discard }\end{array}$ & 180 & $\mathbf{1 1 2}$ & $\mathbf{1 2 2}$ & $\mathbf{1 8 2}$ & $\mathbf{8 4}$ & $\mathbf{1 0 4}$ & $\mathrm{P}<0.05$ \\
\hline
\end{tabular}

Number of blood units, transferred in our blood bank from other blood banks was higher during 2020. The utilization of blood and blood products revealed statistically significant higher number during all three months of March to May 2020 as compared to respective months of 2019. The overall discard of blood and blood products was higher in 2020, except month of March.

Table 2: Showing Comparative Data Of Blood Units Collection In Blood Bank And Camps During March To May 2019 \& 2020

\begin{tabular}{|l|l|l|l|l|l|l|}
\hline \multirow{2}{*}{ Month } & \multicolumn{2}{|l|}{ March } & \multicolumn{2}{l|}{ April } & \multicolumn{2}{l|}{ May } \\
\cline { 2 - 7 } & $\mathbf{2 0 1 9}$ & $\mathbf{2 0 2 0}$ & $\mathbf{2 0 1 9}$ & $\mathbf{2 0 2 0}$ & $\mathbf{2 0 1 9}$ & $\mathbf{2 0 2 0}$ \\
\hline Collection in Blood bank & 527 & 509 & 438 & 178 & 674 & 237 \\
\hline Collection in camps & 88 & 244 & 368 & 630 & 70 & 498 \\
Urban & 79 & 192 & 302 & 259 & 51 & 135 \\
Rural & 09 & 42 & 66 & 371 & 19 & 363 \\
\hline Total Collection & 615 & 753 & 806 & 808 & 744 & 735 \\
\hline
\end{tabular}

Table 2, clearly depicts that there was gradual decrease in, in-house VBD collection during the lockdown period while collection of blood from voluntary blood donation camps exceeded during the same 
months of 2020. More VBD camps could be organised in rural areas than in the city limits. Blood donors were unable to reach the mother blood bank due to implementation of lockdown in the city. Even with granting of special permission, the donors showed reluctance to visit blood bank for fear of getting infected, as COVID-19 Hospital was established in the Hospital campus.

Table 3: Showing Comparative Data Of TTD Positivity During March To May 2019 \& 2020

\begin{tabular}{|l|l|l|l|l|l|l|}
\hline Month & March & \multicolumn{2}{|l|}{ April } & \multicolumn{2}{l|}{ May } \\
\hline Test & $\mathbf{2 0 1 9}$ & $\mathbf{2 0 2 0}$ & $\mathbf{2 0 1 9}$ & $\mathbf{2 0 2 0}$ & $\mathbf{2 0 1 9}$ & $\mathbf{2 0 2 0}$ \\
\hline Hepatitis B Virus (HBV) & 01 & 02 & 06 & 05 & 06 & 03 \\
\hline Hepatitis C Virus (HCV) & 00 & 00 & 01 & 00 & 00 & 01 \\
\hline $\begin{array}{l}\text { Human immunodeficiency } \\
\text { virus (HIV) }\end{array}$ & 01 & 01 & 00 & 01 & 00 & 00 \\
\hline $\begin{array}{l}\text { Venereal Disease Research } \\
\text { Laboratory test (VDRL) }\end{array}$ & 00 & 00 & 00 & 00 & 00 & 00 \\
\hline Total & 02 & 03 & 07 & 06 & 06 & 04 \\
\hline
\end{tabular}

All the blood and blood products were tested for Hepatitis B Virus (HBV), Human immunodeficiency virus (HIV), Hepatitis C Virus (HCV) and Venereal Venereal Disease Research Laboratory test (VDRL) with standard procedures. No significant difference was observed in the seropositivity of blood units during the parallel months of 2019 and 2020. (Table 3 )

\section{DISCUSSION:}

Corona virus disease 2019 (COVID-19) is a disease caused by novel severe acute respiratory syndrome corona virus 2 (SARS-CoV-2) and was first detected in China in December, 2019. ${ }^{2}$ The viral disease has posed a medical emergency and a global crisis. World Health Organization (WHO), declared COVID- 19 as a global pandemic on 11 th March 2020. ${ }^{1}$ SARS-CoV-2 is a novel strain of Corona virus, which has not been previously identified in humans. Transmission of COVID-19 virus among humans is rapid and occurs via close contact with an infected individual who produces respiratory droplets. ${ }^{3,4,5}$ The risk of transmission of COVID-19 through transfusion of blood and blood components is theoretical and likely minimal.

COVID 19 pandemic has affected many sectors of healthcare. Due to initial lack of knowledge about the disease and preparedness to face the pandemic, immediate steps had to be taken on emergency basis to handle the situation. Guidelines were received by blood banks to maintain adequate supply of blood and blood products from time to time.

Our Institute being a Tertiary care centre, treatment of patients other than COVID 19 cases was not much hampered in spite of the viral pandemic. Emergency surgical procedures that require availability of blood continued. Regular demand of blood units for patients of hemoglobinopathies, leukemias and other cancers was persistent and increasing during this period. Maintaining adequate stock of tested blood in blood bank was the main challenge.

Blood banks all over the world are dependent on voluntary blood donation by healthy individuals to maintain adequate stock of blood units. VBD comes through individual donors walking in blood banks and blood camps organized in nearby places. Young and middle aged voluntary donors have shown exemplary courage during this pandemic.

With outbreak of Novel SARS-CoV2 infection, a period of confusion and chaos persisted for initial weeks of March 2020. Due to the fear of COVID 19 infection voluntary blood donation was not optimum in blood bank as the donors were afraid to visit the blood bank, situated in hospital premises. Blood donation in our blood bank dwindled gradually from March to April 2020 and regained in the Month of May 2020. During the period of lockdown our centre had to depend more on voluntary blood donation camps organised up to $150 \mathrm{~km}$ radius from the mother blood bank.

News of warlike situation especially of COVID 19 infection related fatalities in other countries instilled fear and feeling of uncertainty amongst general public. However, soon the better sense prevailed upon the masses and people responded to call for VB donation through camps favourably.

Timely permission was granted for VBD camps from Municipal
Commissioner and District Collector. Guidelines came from State Blood Transfusion Council ${ }^{7,8}$ in March 2020 followed by guidelines from National Blood Transfusion Council', Ministry of Health and family welfare ${ }^{10}$, and FDA. ${ }^{11}$ Organising VBD camps thus became possible.

For VBD Camps, we included detailed travel history of the donor and his contact in the donor screening form. Occurrence of recent symptoms of fever, cough, weakness etc was enquired specifically in every donor.

Prospective donors were examined for fever with digital infrared gun thermometer, in addition to routine check of parameters of weight, blood pressure and haemoglobin estimation.

During camps arranged in rural as well as urban areas, well ventilated halls were selected at camp site to ensure social distancing of atleast one meter in between adjacent donor couches.

Every donor was asked to wear a mask and make use of hand sanitizer before going for blood donation. As seen from Table 2, more VBD camps could be organised with proper arrangements in rural areas as compared to urban areas, as some areas in the city were included in the containment zones.

During the pandemic, non-urgent, elective surgeries were postponed or cancelled that marginally reduced the need for blood units. However our centre being tertiary care hospital and our blood bank is the bigges one of the region, we needed to provide blood units to other government blood banks in emergency situation.

Maintaining stock of tested and safe blood by testing of blood units for transfusion transmitted disease is an essential and routine practice. The number and positivity pattern for TTD remained unchanged over the period.

During strict initial lockdown, we came across following difficulties-

1.Organisation of VBD camps in city due to area quarantine

2.Non-availability of testing kits for TTD

3 . Shortage of reagents and consumables

4.Maintenance and repairs of instruments

Procurement of reagents, testing kits was undertaken from local dealers with administrative help from Institutional Heads. Special permissions and passes were obtained for movement of material and personnel. With cooperation of all blood bank personnel, our blood bank could maintain adequate blood stock.

Complete health care system needs, upgradation of medical facilities and make advances in related research to successfully fight the critical pandemic situations. ${ }^{12}$

In conclusion, routine activities of our blood bank were not affected during initial months of COVID-19 pandemic. Timely guidelines from the concerned authorities, administrative support and proper mobilization of available resources made this possible.

\section{Acknowledgements:}

We acknowledge cooperation of technical, nursing staff and medical health workers, working in blood bank during this pandemic period. We are thankful to Head of the Institute for granting permission to publish the data.

\section{REFERENCES:}

1. World Health Organization. Coronavirus disease (COVID-19) pandemic. https:// www.who.int/emergencies/diseases/novel-coronavirus-2019

2. Coronavirus Disease 2019 (COVID-19) Epidemiology, Pathogenesis, Diagnostics an therapeutics Medical Virology: from Pathogenesis to Disease Control Series Editor: Shailendra K. Saxen

3. Chan JF et al, (2020a) A familial cluster of pneumonia associated with the 2019 novel coronavirus indicating person-to-person transmission: a study of a family cluster. coronavirus indicating person-to-person transmission: a study of a family

4. Ghinai I et al, COVID-19 Investigation Team (2020) First known person-to-person transmission of severe acute respiratory syndrome coronavirus 2 (SARS-CoV-2) in the USA. Lancet. pii: S0140-6736 (20)30607-3. https://doi.org/10.1016/S01406736(20)30607-3

5. Rajgopal T. COVID-19: Epidemiology and public health aspects. Indian J Community Med 2020;45:111-6.

6. Maintaining a safe and adequate blood supply during the pandemic outbreak of coronavirus disease (COVID-19): interim guidance. World health organization. Dated 20 arch 2020

State blood transfusion Council Maharashtra state. No.SBTC/Voluntary blood donation 2020/214 dated 27.03.2020 
8. State blood transfusion Council Maharashtra state. No.SBTC/Blood donation camp $/ 2020 / 240$ dated 13.05 .2020

9. National blood transfusion council, Ministry of Health and Family Welfare,Government of India. D.O.no.S-12016/56/2020-NACO (BS) Dated 25 march 2020

10. Ministry of Health and Family Welfare, Government of India. COVID-19 India. https://www.mohfw.gov.in/

11. Government of Maharashtra, food and drug administration. Letter dated 22/05/2020

12. Pranab Chatterjee et al, The 2019 novel coronavirus disease (COVID-19) pandemic: A review of the current evidence Review Article Indian J Med Res 151, February \& March 2020, pp 147-159 DOI: 10.4103/ijmr.IJMR_519_20 